day care who would benefit from a transfer to the new service. Most of them were epileptics well controlled with medication. But their parents objected to the transfer on the grounds that there were no nurses and no ambulances at the training centre. To date, there are still no nurses and no ambulances and the parents have not changed their opinion. The appointment of a liaison nurse could make such transfers easier in the future.

Unfortunately, when all the bids for joint finance were considered, this bid came fifth on the priority list. I know from experiences in the past, that the first two bids get funded only for the next year, but I plan to resurrect this bid every year until it becomes a top priority. As a way forward towards an integrated use of personnel at the service of mentally handicapped persons, it ought to become a priority. It is one facet of Griffith's integrated care in the community. I agree with $\mathrm{Dr}$ Kearns that a similar appointment elsewhere would solve the problem he has highlighted.

B. N. NwULU

Beachcroft Unit

District General Hospital

Rotherham, S. Yorks.

\section{Request for ideas for feature films}

DEAR SIRS

We are a film company looking for contemporary or historic stories with personal injustice themes to be developed into feature film ideas. These stories could be set within the perimeters of corporate or political prejudices across the spectrum to love tangles, racial discrimination and others.

We feel that the medical profession would be privy to some fascinating case histories ranging from physical injury to mental illness, including memory loss, that would not only be interesting to the public but would also give them a greater understanding of these disabilities.

We would be grateful if readers could come forward with brief outlines of patients that have stood out in their minds. We realise the difficulty in discussing these confidential cases, but do assure respondents of the utmost discretion and in the event of our discussing this with the person concerned, we would of course deal with it in a most tactful way.

One should consider that the most powerful stories are nearly all based on truth, sympathy for the main character being essential, and the simplest of ideas can become very strong film material. Three obvious examples are 'Children Of A Lesser God', 'One Flew Over The Cuckoo's Nest' and more recently 'Rainman'.
If any respondent feels that it would be more beneficial to have a face-to-face discussion on this matter, we would be very happy to do so.

\section{The Jim Lee Film Company \\ 71 Summer Place Mews}

JIM LEE

London SW7 3EF

\section{Open letter-Review of research on family therapy and family based \\ intervention}

\section{Dear Colleague}

This is a note requesting your help.

I am currently carrying out a literature review of research into family therapy and other forms of family intervention in the British Isles. I should appreciate it if you would send me references to your work in this field or, preferably, offprints of your papers.

I am particularly interested in tracking down unpublished dissertations and papers. If you, or indeed your students or colleagues, have written unpublished work, I should be grateful if you would let me know how this may be accessed.

Let me outline the scope of the review. All traceable unpublished and published empirical studies carried out in the British Isles between 1959 and 1989 that fall within the areas outlined below will be included. Case studies and anecdotal accounts of treatment process and outcome will be excluded. All other studies, however methodologically weak, will be considered.

Although the central concern of the review is family therapy, studies of other forms of family intervention are also being traced. The following is a list of those forms of intervention covered by the review.

Family therapy with families where the child, the parents or the grandparents have a presenting problem or where relationship difficulties are identified as the reason for seeking therapy.

Marital therapy with distressed couples or couples seeking to enrich their relationship.

Family conciliation counselling with families where separation or divorce is occurring.

Family bereavement counselling with families where a member has died or suffers from a fatal illness.

Sex therapy for couples who present with psychosexual difficulties.

Psychosocial family interventions to prevent relapse in schizophrenia where a high level of expressed emotion is present in the patient's family. 